\title{
OS BOLIVIANOS COMERCIANTES DE HORTALIÇAS NA FEIRA LIVRE DE LADÁRIO
}

The Bolivian vegetable traders at the fair of Ladário

Los bolivianos comerciantes de verduras en la feria libre de Ladário

\author{
Leonardo Barbosa Araújo* \\ Elisângela de Souza Cunha e Silva** \\ Edgar Aparecido da Costa*** \\ •PPG Estudos Fronteiriços/UFMS - leoaraujo.asp@gmail.com \\ **Geografia/UFMS - elisangelasouzacunha@gmail.com \\ **PPG Estudos Fronteiriços/UFMS - edgarac10@gmail.com
}

Recebido em 18/03/2020. Aceito para publicação em 26/03/2020

Versão online publicada em 05/05/2020 (http://seer.ufrgs.br/paraonde)

\section{Resumo:}

Este trabalho tem por objetivo caracterizar o comércio de hortaliças realizado por feirantes bolivianos na feira livre de sábado na cidade de Ladário, na fronteira Brasil-Bolívia. Utiliza-se de pesquisa de campo com a técnica da observação, tendo por ferramenta o diário de campo. Observou-se que as assimetrias entre as cidades gêmeas Ladário, Corumbá, Puerto Quijarro e Puerto Suárez funcionam como indutoras de interações comerciais e culturais. Notam-se estratégias comerciais baseadas nas complementaridades.

Palavras-chave: Fronteira. Complementaridades. Territorialidades.

\begin{abstract}
:
This paper aims to characterize the vegetable trade made by Bolivian fairers at the Saturday free fair in the city of Ladário, on the Brazil-Bolivia border. Field research is used with the observation technique, using the field diary as a tool. Asymmetries between the twin cities Ladário, Corumbá, Puerto Quijarro and Puerto Suárez have been observed to induce commercial and cultural interactions. Commercial strategies based on complementarities are noted.
\end{abstract}

Key-words: Border. Complementarities. Territoriality.

\section{Resumen:}

Esta obra pretende caracterizar el comercio de hortalizas realizado por los fairers bolivianos en la Feria Libre del sábado en la ciudad de Ladário, en la frontera entre Brasil y Bolivia. La investigación de campo se utiliza con la técnica de observación, utilizando la herramienta Diario de campo. Se observó que las asimetrías entre las Ciudades Gemelas Ladário, Corumbá, Puerto Quijarro y Puerto Suárez actúan como inductores de interacciones comerciales y culturales. Se observan estrategias comerciales basadas en complementariedades.

Palabras-clave: Frontera, Complementariedades, Territorialidad. 


\section{Introdução}

Fronteiras são objetos de análise complexos. Sua apreensão e percepção apresentam significados diferentes para os Estados que a compõe, para os cidadãos fronteiriços e também para o meio acadêmico. Sua compreensão está diretamente relacionada ao entendimento de território. Para Souza (2000, p. 86) é preciso ver o território como:

[...] um campo de forças, uma teia ou rede de relações sociais que, a par de sua complexidade interna, define, ao mesmo tempo um limite, uma alteridade: a diferença entre "nós" (o grupo, os membros da coletividade ou "comunidade", os insiders) e os "outros" (os de fora, os estranhos, os outsiders).

O limite é a linha definidora da jurisdição territorial. A fronteira é uma extensão de terras que contém o limite, não necessariamente no seu meio. É nela que são estabelecidas as relações sociais, as territorialidades. A fronteira envolve uma área com um imbricado de tramas territoriais que passa pela comunicação, pelas mobilidades, relações de trocas, redes, trabalho entre seus moradores e, inclusive apropriação territorial (SAQUET e GALLO, 2015).

Interessa neste trabalho a fronteira Brasil-Bolívia, notadamente a área compreendida pelas cidades de Corumbá e Ladário, localizadas na porção ocidental do estado de Mato Grosso do Sul (Brasil) e Puerto Quijarro e Puerto Suárez, na parte oriental do departamento de Santa Cruz (Bolívia). As brasileiras, fundadas como apoio no controle de fronteira em 1778, são cerca de 100 anos mais antigas que Puerto Suárez, fundada em 1875, nas bordas da Laguna de Cáceres. Puerto Quijarro é mais jovem e tem sua fundação ligada a construção da estação ferroviária de ligação entre Brasil-Bolívia, em 1950 (COSTA, 2013).

Trata-se de um espaço fronteiriço com uma característica marcante - a fluidez, explicada, em parte, pelo processo histórico de construção. A passagem de fronteira entre as cidades é frequentemente movimentada pelas mobilidades territoriais de residentes fronteiriços, turistas e mercadorias para ambos os lados (COSTA, 2013). Para Souza (2014, p.66) a fluidez territorial é uma consequência das mobilidades humanas em função das infraestruturas e depende "das condições materiais e imateriais que garantam a circulação de pessoas, de mercadorias, de serviços, de ideias e de informações, fomentando a integração física regional".

O objetivo deste trabalho é caracterizar o comércio de hortaliças realizado por feirantes bolivianos na feira livre de sábado na cidade de Ladário, na fronteira Brasil-Bolívia. Para tanto, utilizou de trabalho de campo, apoiandose na técnica da observação durante dois sábados do mês de julho de 2019. A contagem das bancas, suas características e organização, bem como a percepção das interações dos feirantes com os consumidores foram registrados num caderno de campo. Posteriormente, as anotações foram agrupadas e categorizadas com a finalidade de produzir um entendimento do objetivo proposto.

$\mathrm{O}$ artigo foi organizado em duas partes. Primeiramente busca-se trazer a

ParaOnde!?, Porto Alegre, v.13, n.2, p.183-195, 2020.http://seer.ufrgs.br/paraonde Edição Especial - VII Seminário Internacional de Estudos Fronteriços 
compreensão teórica sobre as fronteiras e seu sentido de complementaridades. Em seguida, apresenta-se os elementos da venda de hortaliças pelos bolivianos na feira livre de Ladário.

\section{Fronteira como espaço de complementaridades}

Fronteira e faixa de fronteira não são sinônimos, apesar de produzirem algumas confusões. As fronteiras são espaços de contato entre dois países formando uma ou mais díades (FOUCHER, 2009). São áreas passíveis de ocupação, de interação e de trocas comerciais, culturais, laborais, dentre outras (COSTA, 2011).

O termo faixa de fronteira começou a ser usado em 1974 para definir uma margem de terras que abrange $150 \mathrm{~km}$ contadas a partir do limite internacional, obedecendo aos delineamentos de cada unidade territorial. Esse espaço foi criado sob a visão de se ter segurança nacional. Não obstante, observa-se um espaço deficitário de políticas públicas com vistas à oportunidade de desenvolvimento (MACHADO et al., 2005).

A faixa de fronteira é uma entidade geopolítica e não permite a noção exata da permeabilidade e porosidade presentes/ausentes nas passagens de fronteira. Trata-se de um conceito que interessa diretamente a segurança nacional. Neste trabalho interessa muito mais a percepção dos fluxos e dos relacionamentos fronteiriços. Neste sentido, o conceito de espaço fronteiriço é mais apropriado, pois, permite a leitura das mobilidades territoriais e os fluxos de mercadorias entre os territórios que compõem a fronteira.

Cabe ressaltar, que essa condição de periferia é fortemente rejeitada pelos fronteiriços. Nogueira (2007, p.32) comenta que "a fronteira política impõe, por necessidade do Estado, uma disjunção histórica, um corte que institui uma diferença, que dificulta uma identidade fronteiriça, e que a sociedade fronteiriça procura romper".

Além disso, a condição periférica contribui para um engajamento na busca de soluções para os problemas no nível local. Assume-se o pressuposto que as fronteiras possuem algum nível de trocas locais, espontâneas ou promovidas, num movimento de complementaridades boas ou não (MAX e OLIVEIRA, 2009; OLIVEIRA, 2005).

\section{Para Oliveira (2005, p.382):}

[...] as fronteiras por manterem uma importante interdependência com o exterior, muito maior que outras regiões, se apresentam, no quadro das novas tendências descentralizadoras, com maiores níveis de capacidade para complementariedades e, até competitividade nos mercados internacionais (sobretudo os mais próximos).

As assimetrias são importantes elementos de indução das mobilidades territoriais. Conforme Steiman e Machado (2002), as trocas nos espaços fronteiriços tendem a ser mais intensas quanto mais assimétricas forem os territórios componentes da fronteira. Por isso, são consideradas, neste trabalho, como espaço de complementaridades.

ParaOnde!?, Porto Alegre, v.13, n.2, p.183-195, 2020.http://seer.ufrgs.br/paraonde Edição Especial - VII Seminário Internacional de Estudos Fronteriços 
Milton Santos faz uma análise das complementaridades regionais que, também, podem ser aplicadas ao contexto fronteiriço. Segundo ele:

As especializações do território, do ponto de vista da produção material, assim criadas, são a raiz das complementariedades regionais: há uma nova geografia regional que se desenha, na base da nova divisão territorial do trabalho que se impõe (SANTOS, 1996, p. 41).

Santos (1996) entende que a especialização territorial gera uma necessidade maior de circulação de mercadoria, aumentando as complementaridades regionais. De certa forma se estabelece uma divisão territorial do trabalho e especializações produtivas espaciais. As mobilidades fronteiriças são estimuladas pelos mesmos vetores territoriais, discutidos por Milton Santos.

Inúmeras são as estratégias desenvolvidas nos espaços fronteiriços para a resolução de problemas, como o relativo isolamento geográfico e a escassez de produtos nos comércios locais. Os atores fronteiriços identificam em ambos os lados da fronteira vantagens comerciais como preços e disponibilidade de mão-de-obra mais barata. Isso também se aplica a serviços essenciais como saúde e educação. Sobre este cenário, Ferrari (2013, p.96) pontua que:

Para fugir aos controles políticos territoriais, os fronteiriços, desenvolvem estratégias para assegurar a continuidade das interações, notadamente daquelas econômico-comerciais, nem sempre concebidas por eles como transgressivas dos territórios nacionais. O que era contrabando descaminho para os Estados nacionais, eram trocas complementares para os fronteiriços das cidades gêmeas.

Ao analisar as interações transfronteiriças nas cidades gêmeas de Dionísio Cerqueira/Barracão/Bernardo de Irigoyen e San Antonio/Santo Antônio do Sudoeste, Ferrari (2013) destaca que, apesar das ideologias distintas de Brasil e Argentina, ambas tinham como propósito geopolítico o fortalecimento das identidades nacionais, enquanto que os moradores locais buscavam a integração físico-social. Historicamente foram construídas relações de parentesco, instalação de residências, práticas laborais tornando os espaços com amplo significado para as complementaridades socioterritoriais. A ausência de instituições de controle deu lugar à integração desses povos fronteiriços.

Resultados parecidos com os de Ferrari (2013) foram encontrados por Teka et al. (1999) ao analisarem o comércio transfronteiriço no Sul e Sudeste da Etiópia. Os autores observaram que fatores como a relativa homogeneidade geográfica, cultural e étnica, bem como da produção e das características de consumo funcionavam como indutores para o dinamismo comercial fronteiriço. Ao longo da fronteira da Etiópia com o Quênia identificaram um perfil comum nos comerciantes de gado formando uma concentração geográfica, religiosa e étnica. Percebeu-se que os Oromos e os Somalis dominam o comércio transfronteiriço e que a maioria desses comerciantes possui parentes em ambos os países e também cartões de identidade válidos em três países.

ParaOnde!?, Porto Alegre, v.13, n.2, p.183-195, 2020.http://seer.ufrgs.br/paraonde Edição Especial - VII Seminário Internacional de Estudos Fronteriços 
Logo, o fronteiriço tem um outro jeito de perceber os controles. A explicação pode residir no seu cotidiano, nas territorialidades traçadas para além dos limites internacionais. Nas palavras de Oliveira et al. (2011, p. 80), "a condição fronteiriça funcionaliza a estrutura produtiva e ocupacional em decorrência das vantagens comparativas localizadas, condicionando o tecido urbano".

Nessa lide, Max e Oliveira (2009, p. 22) afirmam que a busca pelas complementaridades motivadas pelas assimetrias territoriais passa pelos "acordos implícitos, os julgamentos de valor e um necessário clima de confiança". Ferrari (2013) afirma que as interações nas cidades gêmeas são materiais e imateriais. O cotidiano dos fronteiriços é moldado por laços de solidariedade, amizade, parentesco e outras relações de afinidade social, como o com $\neg$ padrio. Existem racionalidades econômicas, mas não são apenas elas que movem a fronteira.

Há de se considerar, então, que os modelos de gestão dos territórios fronteiriços devem ser construídos pelos Estados com base nas especificidades destas regiões. Nesse sentido, "a gestão territorial em área de fronteira deve ser levada a cabo com a representatividade local dos Estados limítrofes, para que as ações em ambos os lados do limite possam convergir em benefício da região" (DIAS JUNIOR, CRIVELATTI e COSTA, 2013, p. 43).

Analisando as práticas operacionais entre os fronteiriços, Machado et al. (2005) considera duas possibilidades de integração econômica: funcional e formal. A abordagem formal, no sentido deste trabalho, pode ser exemplificada no relacionamento dos agricultores com órgãos públicos, como a UFMS, Marinha, Prefeitura de Corumbá e de Ladário, dentre outros. Por outro lado, a abordagem funcional está presente nas estratégias comerciais desses agricultores, ao comercializarem com feirantes, nacionais e bolivianos. Para Oliveira (2005) essas estratégias buscam aproveitar as oportunidades resultantes da transversalidade do comportamento populacional nas fronteiras. É o que acontece nas feiras livres, abordado em seguida.

\section{A venda de hortaliças pelos bolivianos na feira livre de Ladário}

As feiras livres são espaços de comercialização e de sociabilidade (VEDANA, 2004). De acordo com Sato (2007), as feiras livres são verdadeiras redes de comunicação estabelecidas numa dada localidade. Sua realização tem uma sintonia direta com o bairro em que acontece. Suas feições, mesmo que sensíveis, apresentam mudanças, pois mudam seus frequentadores. As cores, as estruturas, arranjos e variedades encontradas nas feiras, funcionam como um chamariz para a venda. Para Sato (2007, p. 97) "cada banca se apresenta como uma verdadeira e virtuosa vitrine, que deve ser somada a uma boa performance do feirante ao anunciar seus produtos". Assim, a feira de sábado em Ladário é diferente das outras feiras que acontecem diariamente, em bairros diferentes, de Corumbá.

O município de Ladário está situado na porção ocidental do Estado de

ParaOnde!?, Porto Alegre, v.13, n.2, p.183-195, 2020.http://seer.ufrgs.br/paraonde Edição Especial - VII Seminário Internacional de Estudos Fronteriços 
Mato Grosso do Sul, na fronteira do Brasil com a Bolívia. A área urbana possui $5,8 \mathrm{~km}^{2}$ e fica a $421 \mathrm{~km}$ da capital (Campo Grande), a $6 \mathrm{~km}$ do centro de Corumbá e a $12 \mathrm{~km}$ da linha do limite internacional com a Bolívia. É um enclave territorial dentro do município de Corumbá (Figura 1) e conta com 22.968 habitantes (IBGE, 2018). A economia municipal baseia-se na pecuária, na pesca, no turismo, no transporte de navegação e mineração (CUYATE, COSTA e BRATICEVIC, 2015).

Ladário não possui terras que tocam diretamente o limite internacional do país, mas pode ser caracterizado como município fronteiriço, pois é parte de um conjunto de localidades interligadas, que Benedetti (2011) classifica como sistema fronteiriço disperso. Em outras palavras, "forma uma urbanização descontínua em ambos os lados da fronteira Brasil-Bolívia" (CUYATE, COSTA e BRATICEVIC, 2015, p. 5).

\section{Figura 1 - Localização geográfica do município de Ladário-MS, Brasil.}

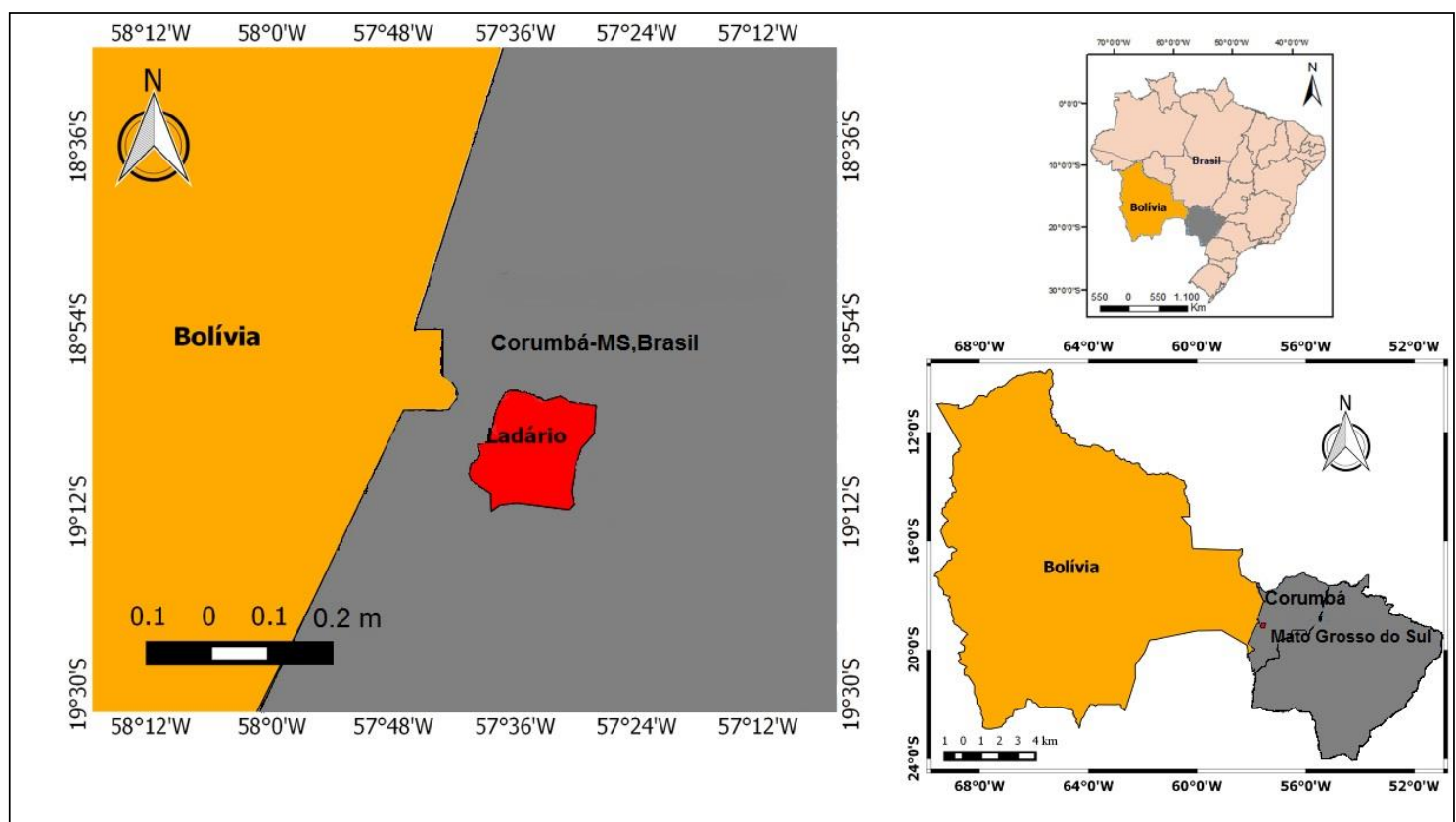

Fonte: Cuyate, Costa e Braticevic (2015, p. 5).

Existem três feiras livres semanais na cidade de Ladário: uma quartafeira e outra no sábado, pela manhã, no mesmo local - trechos das ruas Conde de Azambuja, Comandante Souza Lobo e do Couto; a outra acontece na quinta-feira à noite, ocupando partes da Rua Nicolas Scaff e Rua Corumbá (Figura 2). 
Figura 2 - Localização das feiras livres de Ladário-MS.

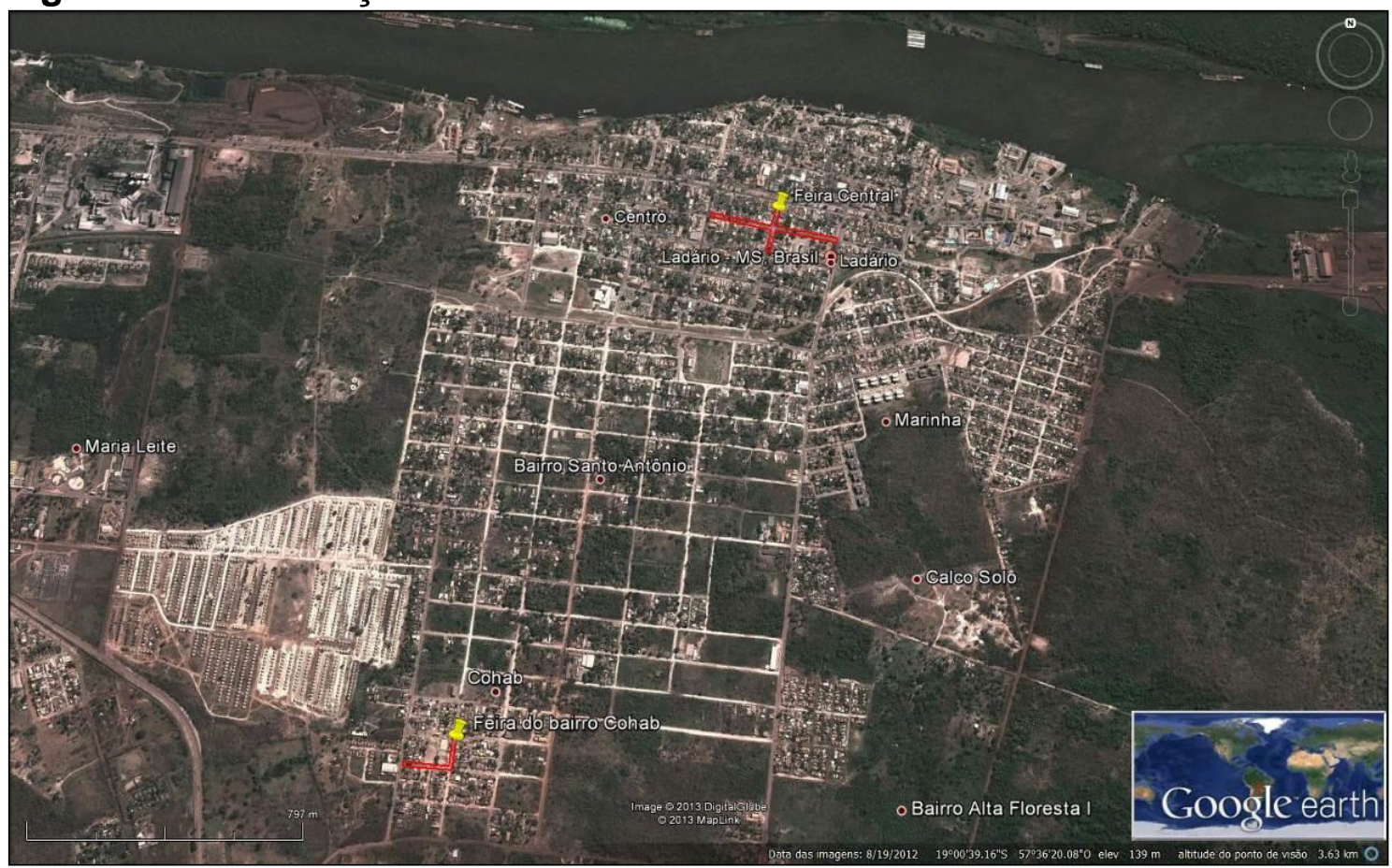

Fonte: Cuyate, Costa e Braticevic (2015, p. 6).

Nas feiras livres de Ladário os feirantes brasileiros e bolivianos comercializam além das hortaliças:

[...] roupas novas e usadas, dvd's, cd's, plantas ornamentais, panelas, espetinhos, brinquedos, acessórios de bicicletas, fraldas descartáveis de várias marcas, produtos considerados de primeira linha como desodorantes, aparelhos de barbear, xampus, sabonetes, creme dental, leite em pó, feijão, alho, etc. São vendidos artesanatos de variados modelos, como bolsas, porta-retratos, utensílios de cozinha, dentre outros. São todos oriundos da Bolívia, inclusive carregam consigo frases como "Bienvenidos a Bolivia", "Santa Cruz, Bolivia", "Bolivia" e outras frases caracterizando o país. Também são encontrados: ventiladores, cobertores, guarda-chuvas, coleiras para cachorros, despertadores, grampeadores, diversos modelos de bijuterias, pastel e salgados, com sucos, refrigerantes etc. (CUYATE, COSTA e BRATICEVIC, 2015, p. 6).

Neste trabalho interessa a caracterização dos feirantes bolivianos de hortaliças, na feira livre de Ladário/MS. Para tanto, foi realizado um trabalho de campo em dois sábados consecutivos do mês de julho/2019. Utilizou-se a técnica da observação e um caderno de campo no qual foram anotados dados sobre o atendimento e sobre a banca, tais como: idioma utilizado, sexo, quantidade de bancas, variedades e qualidade visual dos produtos, organização, interação feirante/consumidor.

Foi observada a presença 21 bancas nas quais os feirantes eram bolivianos. Este número se repetiu nos dois dias de pesquisa. Em todas as bancas as mulheres estavam no comando das atividades de venda. A presença de homens foi notada em algumas delas, mas, somente realizavam

ParaOnde!?, Porto Alegre, v.13, n.2, p.183-195, 2020.http://seer.ufrgs.br/paraonde Edição Especial - VII Seminário Internacional de Estudos Fronteriços 
atendimento quando aparecia uma quantidade de clientes que excedia a capacidade de atendimento da mulher. As crianças são frequentes acompanhando as mães. Em apenas sete bancas não foi observada a presença delas.

Resultados parecidos foram encontrados por Tello et al. (2015), estudando a comercialização de hortaliças nos principais pontos de venda de Tabatinga/AM, onde as mulheres comandam o negócio em $71 \%$ das bancas.

Notou-se que na feira livre estudada existem muitas representações geográficas e culturais, não apenas local. Por ela acontecer num espaço fronteiriço sua paisagem cultural sugere um misto de representações. A organização das bancas, em sua grande maioria, é apoiada num pranchão de madeira e a cobertura de lona azul (Figura 3).

\section{Figura 3- Estrutura das bancas e aspectos visuais de feirantes bolivianas,} Ladário/MS.

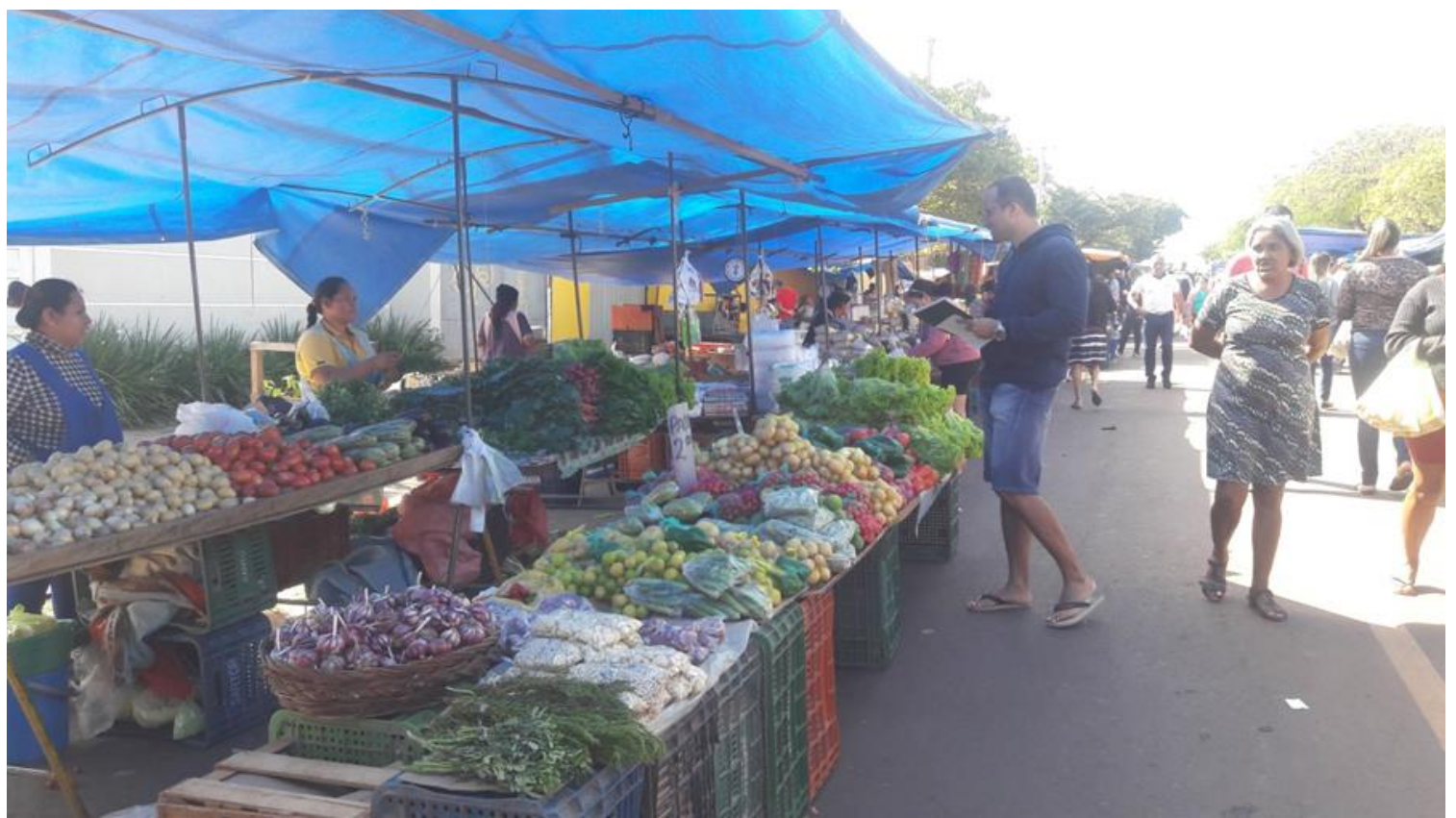

Fonte: trabalho de campo, julho/2019.

Trata-se de uma forma recorrente de organização, adaptada de local para local. Gonçalves e Abdala (2013, p. 5) descrevem a montagem e estrutura de uma banca na feira do bairro Saraiva, na cidade de Uberlândia-MG, da seguinte forma:

A montagem das bancas exige técnica e certo esforço. Primeiro encaixa-se a estrutura de apoio, feita de ferro e em formato de retângulo ou em cavaletes feitos com madeira. Com a estrutura montada, sobrepõe-se o tampo, uma placa de madeira onde os produtos serão expostos. Feito isso, encaixam-se nas laterais da banca as barras que sustentarão o teto com a lona. Por último, estende-se a lona que protegerá o feirante e os fregueses das intempéries do clima. O tempo para a montagem e desmontagem da banca dependerá da habilidade de cada feirante; o mais ágil começa a vender primeiro.

ParaOnde!?, Porto Alegre, v.13, n.2, p.183-195, 2020.http://seer.ufrgs.br/paraonde Edição Especial - VII Seminário Internacional de Estudos Fronteriços 
As feirantes bolivianas se destacam na paisagem cultural das feiras livres por suas saias rodadas, chapéu e trança no cabelo (COSTA et al., 2009). Algo que chama muito a atenção nas suas vestes são os aventais com bolsos na frente que servem para guardar o dinheiro.

As bancas dos feirantes bolivianos são um mosaico de cores. Denotam a presença de variedades adquiridas nos assentamentos rurais de Corumbá e Ladário, das CEASA de Campo Grande e São Paulo, de alguns supermercados ou sacolões de Corumbá, de várias regiões da Bolívia e de alguns outros países da América do Sul (ESPÍRITO SANTO, COSTA e BENEDETTI, 2017). Muitas vendem frutas, legumes e cereais diversos juntamente com as hortaliças. Para o cômputo das variedades, considerou apenas os tipos de hortaliças presentes. Assim, observou-se o predomínio (52,38\%) de bancas que vendem, no mínimo, 15 variedades (Figura 4).

Figura 4 - Variedade de hortaliças observada por unidade de banca dos feirantes bolivianos, Ladário/MS.

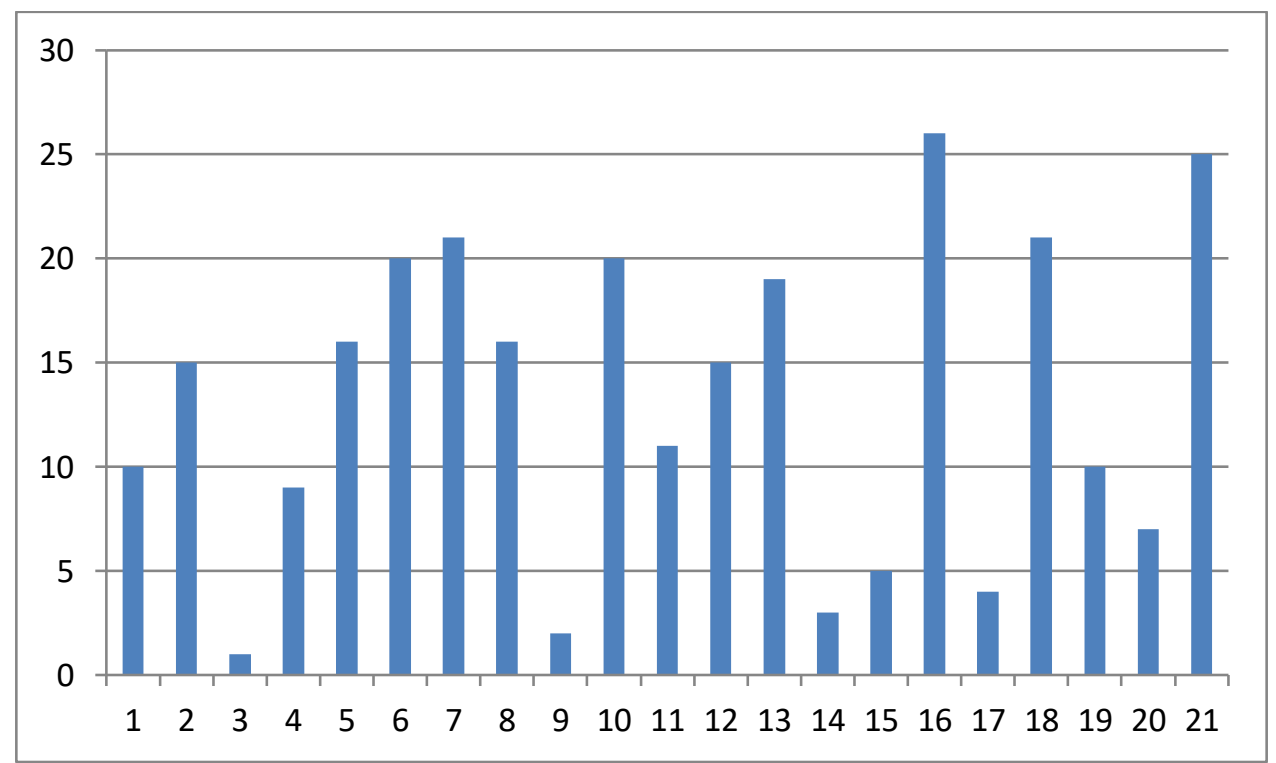

Fonte: trabalho de campo, julho/2019.

Quanto às hortaliças comercializadas, a que mais se destacou foi o alho que apareceu em 16 das 21 bancas de feirantes bolivianos encontrados na feira de sábado (76,19\%). Em seguida destaca-se a cebola e o pimentão vistos em 13 bancas $(61,90 \%)$. A maior comercialização desses produtos se dá por conta da culinária regional e pelo fato de não serem produzidos nos assentamentos rurais brasileiros desta fronteira. Os itens que tem menos encontrados são aqueles que possuem menor procura. São exemplos a batata roxa, conhecida localmente como batata suja, o tomate cereja e o quiabo, vistos em apenas quatro (19,05\%) das bancas (Figura 5).

Nota-se com estes dados um padrão bem diferente em relação a outras regiões do país, onde a alface tem um protagonismo nas vendas. Para Assunção (2013, p.1) "a cultura da alface é largamente difundida em todo o Brasil, sendo considerada a hortaliça folhosa mais consumida em todo o

ParaOnde!?, Porto Alegre, v.13, n.2, p.183-195, 2020.http://seer.ufrgs.br/paraonde Edição Especial - VII Seminário Internacional de Estudos Fronteriços 
território nacional, tendo destaque como cultura de grande importância econômica e alimentar". Notadamente no estado de Goiás, Assunção (2013, p.1) expõe que "dentro da pauta de produtos que são comercializados na CEASA-GO, um dos produtos de maior destaque é a Alface".

Estudos realizados por Cruz et al. (2008, p. 632) nas feiras livres de Bom Jesus, no Piauí conclui que "o tomate e a alface foram as hortaliças mais adquiridas na feira livre". Igualmente, em pesquisa sobre a qualidade da alface comercializada no município de Botucatu-SP, Santos (2010, p. 67) expõe que "entre as hortaliças, a alface é a folhosa de maior valor comercial no Brasil".

Em relação aos processos de comercialização na feira livre, os produtos são expostos de maneira que o consumidor possa observar, tocar e muitas vezes provar e aprovar. A abordagem é direta do feirante ao consumidor e, normalmente, com a seguinte pergunta "o que vai levar?" A pergunta é sempre feita em um tom de voz baixo. Os feirantes bolivianos são bem discretos na questão abordagem ao cliente. Durante a observação percebeu-se que alguns bolivianos proprietários de banca contratam ajudantes brasileiros, que são extrovertidos e oferecem os produtos a todos que estão passando, independentemente de estarem parados ou não nas respectivas bancas.

Figura 5 - Tipos de hortaliças comercializadas por feirantes bolivianos, segundo a quantidade observada por unidade de banca, Ladário/MS.

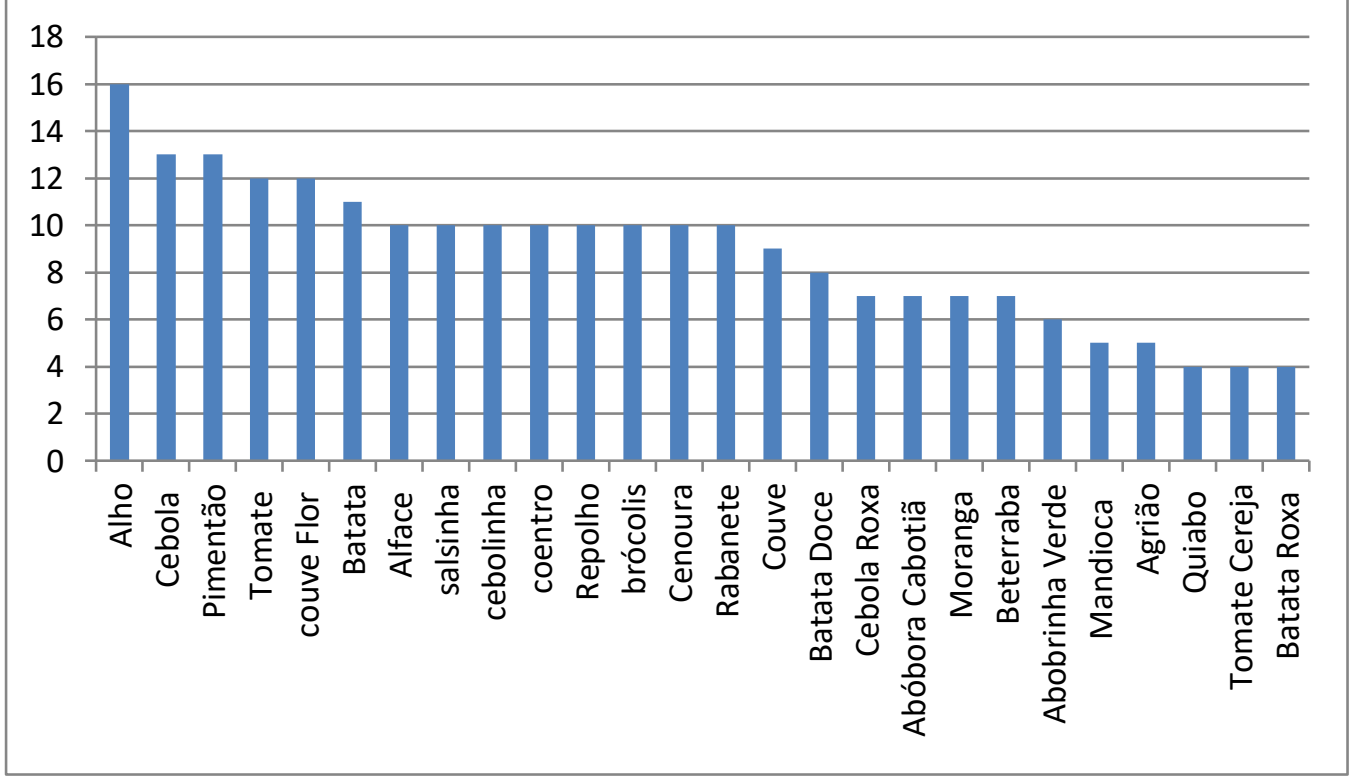

Fonte: trabalho de campo, julho/2019.

A fronteira é um lugar e de múltiplas interações sociais, econômicas e culturais (COSTA et al., 2009). Estabelece-se um território temporário, definido pela relação feirante/consumidor. O deslocamento de pessoas de um lado para o outro da fronteira promove a interação de pessoas de diferentes culturas na feira livre e isso contribui para que aconteça um cruzamento linguístico do português/Brasil e do espanhol/Bolívia, surgindo o "portunhol". Para Motta (2005), o portunhol é o nome dado a mistura das línguas, português e espanhol, utilizada no sentido de um diálogo imediato e informal. É relevante

ParaOnde!?, Porto Alegre, v.13, n.2, p.183-195, 2020.http://seer.ufrgs.br/paraonde Edição Especial - VII Seminário Internacional de Estudos Fronteriços 
frisar que o atendimento, em sua maioria, é feito em "Portunhol" (80,95\%).

De acordo com Sato (2007), a feira tem o sentido de festa, mas funciona como locais de comercialização de produtos, trabalho e de relações sociais. Nela são produzidas relações de sociabilidade, independente da língua falada (VEDANA, 2004; SATO, 2007). É um verdadeiro caldeirão cultural. A mercadoria é a mola mestra dos relacionamentos.

\section{Considerações finais}

O propósito deste trabalho foi o de caracterizar o comércio de hortaliças realizado por feirantes bolivianos na feira livre de sábado na cidade de Ladário, na fronteira Brasil-Bolívia. Observou-se nas feiras livres de sábado, em Ladário, uma rede de comunicação estabelecida entre brasileiros e bolivianos, como estratégia comercial de venda.

Ao explorar diferentes traços culturais, os feirantes bolivianos perceberam ser uma boa estratégia de marketing contratar ajudantes brasileiros nas suas bancas. Notou-se a presença maciça das mulheres no comando dessas bancas. Além disso, verificou-se que a extensa variedade de produtos adquiridos e comercializados pelos bolivianos possuem origens diversas (Brasil, Bolívia e outros países sul-americanos).

Pode-se observar a complementaridade nas relações comerciais fronteiriças. Seja nos aspectos culturais, nas origens dos gêneros agrícolas e até mesmo no cruzamento linguístico do português/Brasil e do espanhol/Bolívia, surgindo o "portunhol". As assimetrias são marcantes nesta fronteira e, neste caso, são promotoras de uma intensa interação.

Laços de solidariedade, amizade, parentesco, são criados e fortalecidos no cotidiano dos fronteiriços em meio as territorialidades ali presentes, permeadas por forças de naturezas políticas, econômicas e identitárias. É nesse complexo sistema que a fronteira se molda e se materializa. A feira é um dos palcos dessas tramas territoriais.

\section{Referências}

ASSUNÇÃO, Paulo Eterno Venâncio. Relações de preços na comercialização de alface em Goiânia. Scientia Plena, v. 9, n. 7 (A), p. 1-12, 2013.

BENEDETTI, Alejandro Gabriel. Lugares de frontera y movilidades comerciales en el sur sudamericano: una aproximación multiescalar. In. COSTA, E.A.; COSTA, G.V.L.; OLIVEIRA, M.A.M. (Orgs). Fronteiras em foco. Campo Grande: Ed. UFMS, 2011. p. 33-55.

COSTA, Edgar Aparecido da. Mexe com o que? Vai pra onde? Constrangimentos de ser fronteiriço. In. COSTA, E.A.; COSTA, G.V.L.; OLIVEIRA, M.M.M. (Orgs.). Fronteiras em foco. Campo Grande: Ed. UFMS, 2011. p.131-170.

ParaOnde!?, Porto Alegre, v.13, n.2, p.183-195, 2020.http://seer.ufrgs.br/paraonde Edição Especial - VII Seminário Internacional de Estudos Fronteriços 
COSTA, Edgar Aparecido. Mobilidade e fronteira: as territorialidades dos jovens de Corumbá, Brasil. Revista Transporte y Territorio, n.9, p. 65-86, 2013.

COSTA, Mirane dos Santos et al. Do produtor ao consumidor: integração socioeconomica e cultural em feiras livres na fronteira Brasil-Bolívia. Cadernos de Agroecologia, v. 4, n. 1, dec. 2009.

CRUZ, Pedro Pereira da et al. Perfil dos consumidores de hortaliças da feira livre de Bom Jesus, Piauí. Hortic. bras, v. 26, n. 2, p. S630-S635, 2008.

CUYATE, Rozilene; COSTA, Edgar Aparecido da; BRATICEVIC, Sérgio Iván. Feira livre de Ladário: território de confronto dos camponeses do assentamento 72 e dos feirantes bolivianos de hortaliças. In. SEMINÁRIO DE ESTUDOS FRONTEIRIÇOS, 5. Anais... Corumbá: UFMS, 2015. p. 1-15.

DIAS JUNIOR, Mérces; CRIVELATTI, Quelim Daiane; COSTA, Edgar Aparecido da. Gestão da segurança pública na fronteira Brasil-Bolívia em Corumbá-MS. Segurança Pública \& Cidadania, v. 5, n. 2, p. 33-59, 2013.

ESPIRITO SANTO, Anderson Luís do; COSTA, Edgar Aparecido da; BENEDETTI, Alejandro Gabriel. A feira livre de Corumbá/MS na fronteira Brasil-Bolívia. Bol. geogr., Maringá, v. 35, n. 3, p. 93-108, 2017.

FERRARI, Maristela. Zona de fronteira, ciudades gêmeas e interações transfronteiriças no contexto do MERCOSUL. Revista Transporte y Territorio, n. 9, p. 87-104, 2013.

FOUCHER, Michel. Obsessão por fronteiras. Tradução de Cecília Lopes. São Paulo: Radical Livros, 2009.

GONÇALVES, Alexandre Oviedo; ABDALA, Mônica Chaves. "Na banca do 'seu' pedro é tudo mais gostoso": pessoalidade e sociabilidade na feira-livre. Ponto Urbe [online], v. 12, p. 1-17, 2013.

MACHADO, Lia Osório et al. Bases de uma política integrada de desenvolvimento regional para a Faixa de Fronteira. v.1. Brasília, DF: Ministério da Integração Nacional, 2005.

MAX, Cláudio Zarate; OLIVEIRA, Tito Carlos Machado de. As relações de troca em região de fronteira: uma proposta metodológica sob a ótica convencionalista. Geosul, v. 24, n. 47, p. 7-27, 2009.

MOTA, Sara Santos. O portunhol e sua re-territorialização na/pela escrit(ur)a literária: os sentidos de um gesto político. 2014. 186 f. Tese (Doutorado em Letras) - Programa de Pós-Graduação em Letras. Santa Maria, RS: UFSM, 2014.

NOGUEIRA, Ricardo José Batista. Fronteira: espaço de referência identitária. Ateliê Geográfico, v. 1, n. 2, p. 27-41, 2007.

OLIVEIRA, Tito Carlos Machado de. Território sem limites: estudos sobre fronteiras. Campo Grande: Ed. UFMS, 2005.

OLIVEIRA, Tito Carlos Machado de et al. Cidades de fronteiras e a rede urbana. In: PEREIRA, R. H. M.; FURTADO, B. A. (Org). Dinâmica urbanoregional: rede urbana e suas interfaces. Brasília: Ipea, 2011.

ParaOnde!?, Porto Alegre, v.13, n.2, p.183-195, 2020.http://seer.ufrgs.br/paraonde Edição Especial - VII Seminário Internacional de Estudos Fronteriços 
SAQUET, Marcos Aurélio; GALLO, Alessandro. Fronteira, território e formação do Sul do Brasil. Terra Livre, v. 2, n. 35, p. 89-102, 2015.

SANTOS, Milton. A urbanização brasileira. São Paulo, Hucitec, 1996.

SANTOS, Caio Marcio Guimarães et al. Qualidade de alface comercializada no município de Botucatu-SP. Revista Iberoamericana de Tecnologia Postcosecha, v. 11, n. 1, p. 67-74, 2010.

SATO, Leny. Processos cotidianos de organização do trabalho na feira livre. Psicol. Soc. [online], vol.19, n.spe, p. 95-102, 2007.

SILVA, Leonardo Luiz Silveira da. As condições espaço-temporais das fronteiras dos Estados. Geosul, v. 33, n. 68, p. 313-334, 2018.

SOUZA, Edson Belo Clemente de. Por uma cooperação transfronteiriça: algumas contribuições para as dinâmicas territoriais da fronteira BrasilParaguai. Revista GeoPantanal, v. 8, n. 15, p. 63-78, 2014.

SOUZA, Marcelo Lopes de. O território: sobre espaço e poder, autonomia e desenvolvimento. In: CASTRO, I. E. et al (Org.). Geografia: conceitos e temas. Rio de Janeiro: Bertrand Brasil, 2000. p. 77-116.

STEIMAN, Rebeca; MACHADO, Lia Osório. Limites e fronteiras internacionais: uma discussão históricogeográfica. Rio de Janeiro: Grupo Retis, 2002.

TEKA, Tegegne et al. Cross-border livestock trade and food security in the Southern and Southeastern Ethiopia Borderlands. OSSREA Development Research Report Series, no. 1. Addis Ababa: OSSREA, 1999.

VEDANA, Viviane. "Fazer a feira": estudo etnográfico das "artes de fazer" de feirantes e fregueses da Feira Livre da Epatur no contexto da paisagem urbana de Porto Alegre. 2004. Dissertação (Mestrado em Antropologia Social) Universidade Federal do Rio Grande do Sul, Porto Alegre, 2004. 